\title{
POTENSI TINGGALAN ARKEOLOGIS DI KAWASAN BANDAR UDARA SAM RATULANGI MANADO: Upaya Pelestarian, Pemanfaatan, dan Pengembangan bagi Masyarakat
}

\section{The Potential of Archaeological Heritage Sam Ratulangi Airport Area of Manado: The Effort of Preservation, Utilization, and Development for Society}

\author{
Irfanuddin W. Marzuki \\ Balai Arkeologi Yogyakarta-Indonesia \\ J1. Gedongkuning No. 174, Yogyakarta \\ wd_546@yahoo.co.id
}

Naskah diterima: 14-07-2015; direvisi: 20-08-2015; disetujui: 28-09-2015

\begin{abstract}
The area of Sam Ratulangi airport's Manado has archaeological heritage which has been know as it is closed for public. This research used descriptive method, using inductive reasoning. Meanwhile, the analysis method used morphologyl, technology, and contextual analysis. This research aimed to find out the potential of archaeological heritage in Sam Ratulangi airport area of Manado. In addition to its strategy of preservation the haritage included veilbox, bungker, and waruga. The preservation can be conducted by doing protection, development, and utilization. The preservation both physical and non physical protection. The effort for its development and utilization was conducted for the purpose of science, education, culture, and tourism.
\end{abstract}

Keywords: Veilbox, bunkers, waruga, preservation.

\begin{abstract}
Abstrak
Kawasan Bandar Udara Sam Ratulangi Manado mempunyai potensi tinggalan arkeologis yang selama ini tidak diketahui masyarakat luas, dikarenakan letak tinggalan yang berada dalam kawasan tertutup untuk umum. Penelitian menggunakan metode deskriptif dengan penalaran induktif. Metode analisis menggunakan analisis morfologi, teknologi dan kontekstual. Tujuan penelitian untuk mengetahui potensi tinggalan arkeologis yang terdapat di kawasan Bandar Udara Sam Ratulangi dan strategi pelestariannya. Tinggalan arkeologis yang terdapat di kawasan Bandar Udara Sam Ratulangi meliputi veilbox, bungker, dan waruga. Upaya pelestarian dapat dilakukan dengan cara perlindungan, pengembangan dan pemanfaatan. Upaya perlindungan meliputi perlindungan secara fisik dan non fisik. Upaya pengembangan dan pemanfaatan dilakukan untuk kepentingan ilmu pengetahuan, pendidikan, kebudayaan dan pariwisata.
\end{abstract}

Kata kunci: Veilbox, bungker, waruga, pelestarian.

\section{PENDAHULUAN}

Kota Manado sebelum jatuh ke tangan Jepang merupakan sebuah kotapraja (gementee) yang dipimpin wali kota dengan suatu Dewan Kota. Dewan Kota beranggotakan 11 anggota, yang terdiri dari tujuh bangsa Eropa, tiga Indonesia, dan satu Timur Asing. Tugas Dewan kota merencanakan pembangunan kota, namun belum sempat terealisasi karena datangnya Jepang. Pada masa pemerintahan Jepang tidak terjadi usaha pengaturan kota, yang ada mobilisasi dan pemakaian fasilitas kota untuk kepentingan perang. Pembangunan infrastruktur berupa pembangunan pembangkit listrik di Tonsea Lama dan lapangan terbang Mapanget (Makkelo, 2011: 66-68).

Kedatangan tentara Jepang pertama di Sulawesi Utara melalui pelabuhan Kema dan Manado pada hari Minggu tanggal 11 
Januari 1942. Sebelum pendaratan, tentara Jepang membombardir basis angkatan udara Belanda di Kalawiran dan pelabuhan amphibi di Tasuka (Palar, 2009a: 187). Pada tanggal 4 Februari 1942, tentara Jepang menguasai Manado. Awalnya kedatangan tentara Jepang disambut dengan baik oleh warga Manado, seperti di daerah-derah lain, namun hal itu tidak berlangsung lama. Pada masa penjajahan Jepang, rakyat ditindas dan diperlakukan dengan kejam (Saptaningrum, 2010: 2).

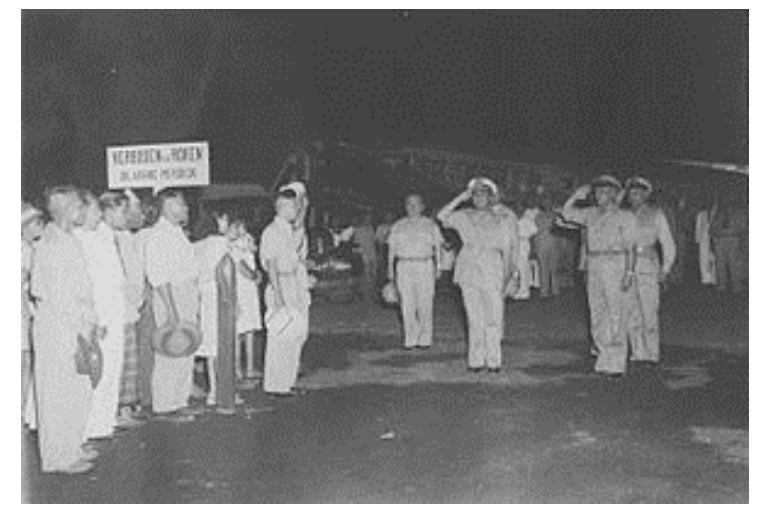

Gambar 1. Penyambutan Menteri presiden Negara Indonesia Timur Ida Anak Agung Gde Agung di lapangan terbang Mapanget tahun 1948 (Sumber: www.tropenmuseum.nl)

Bandar Udara Sam Ratulangi secara administratif berada di wilayah Kota Manado. Sejarah pembuatan Bandar Udara Sam Ratulangi (dahulu dikenal dengan nama Lapangan Terbang Mapanget), dimulai pada masa pendudukan Jepang. Bangunan awal landasan pacu Bandar Udara Sam Ratulangi berukuran panjang $700 \mathrm{~m}$ dan lebar $23 \mathrm{~m}$ (http://samratulangiairport.com/sejarah, diunduh tanggal 22 Juni 2014). Wilayah Bandar Udara Sam Ratulangi dahulu berupa rawa dan semak belukar. Pembangunan dilakukan oleh romusha yang diawasi tentara Jepang dengan meratakan bukit dan menimbun rawa, menggunakan peralatan seadanya. Pembangunan lapangan terbang Mapanget dilakukan siang malam, apabila siang di bom oleh pasukan Sekutu, maka pekerjaan dilakukan pada malam harinya (Palar, 2009b: 213). Untuk menghindari serangan tentara Sekutu, dibangun veilbox dan bungker di sekitar lapangan terbang.

Pada masa pemberontakan Permesta, lapangan udara Mapanget dikuasai oleh Permesta dibawah AUREV (Angkatan Udara Revolusioner). Lokasi lapangan dijadikan sebagai tempat latihan baris berbaris caper (calon prajurit) Permesta. Lapangan Terbang Mapanget akhirnya dapat dikuasai oleh RPKAD dibawah komandan L.B. Moerdany setelah terjadi pertempuran selama dua minggu (Palar, 2009b: 206-207). Pasukan TNI menamakan Lapangan Terbang Mapanget dengan nama Lapangan Udara Tugiman, untuk mengenang Sersan Mayor Tugiman yang gugur ketika terjadi pertempuran di Mapanget (http://samratulangi-airport. com/sejarah, diunduh tanggal 22 Juni 2014). Menurut penuturan Indra (staff PT Angkasa Pura I) dahulu terdapat bangunan bekas markas CIA di kawasan Bandar Udara Mapanget, namun saat ini sudah dibongkar diganti bangunan baru.

Bandar Udara Mapanget dinamai Bandar Udara Dr. Gerungan Saul Samuel Yacob Ratulangi (Sam Ratulangi) seorang pahlawan Nasional yang berasal dari Sulawesi Utara. Bandar Udara Sam Ratulangi terakhir dipugar pada tahun 2001 (www.samratulangi-airport.com/ sejarah, diunduh tgl 22 Juni 2014). Selama pembangunan sampai saat ini, Bandar Udara Sam Ratulangi telah mengalami perubahan yang sangat besar. Hal ini dikarenakan terjadinya peningkatan status sebagai Bandar Udara Internasional. Dalam upaya pembangunan kawasan Bandar Udara terjadi perubahan fisik bangunan sesuai standar Bandar Udara Internasional. Pengelolaan Bandar Udara saat ini dilakukan oleh PT Angkasa Pura I (persero). Pihak pengelola Bandar Udara sering menerima kunjungan dari sekolah mulai TK sampai Perguruan Tinggi untuk mengenal kawasan Bandar Udara Sam Ratulangi. Dengan adanya kunjungankunjungan tersebut, membuat PT Angkasa 
Pura merasa perlu untuk mengetahui lebih jauh potensi tinggalan arkeologi yang terdapat di kawasan Bandar Udara dan upaya pelestarian yang bisa diterapkan. Berdasarkan hal tersebut, permasalahan yang akan dibahas dalam penelitian ini adalah:

1. Apa saja tinggalan arkeologis yang terdapat di kawasan Bandar Udara Sam Ratulangi Manado?

2. Bagaimana upaya pelestarian yang dapat dilakukan terhadap tinggalan arkeologis tersebut.

Tujuan dari penelitian ini adalah untuk mengetahui potensi tinggalan arkeologi yang terdapat di kawasan Bandar Udara Sam Ratulangi, dan bagaimana upaya pelestariannya sehingga bisa dikembangkan dan bermanfaat bagi ilmu pengetahuan, pendidikan, sejarah, pariwisata, dan kebudayaan.

\section{METODE}

Metode penelitian ini bersifat dekriptif analitis, yang berusaha mendeskripsikan dan menginterpretasikan tingggalan arkeologi yang ditemukan secara sistematis, baik bentuk, ukuran, maupun kondisi saat ini (Sumanto, 1995: 77). Penalaran yang di gunakan dalam penelitian berupa penalaran induktif, berdasarkan pengamatan fakta-fakta atau gejala-gejala khusus untuk kemudian disimpulkan sebagai gejala yang bersifat umum atau generalisasi empiris (Tanudirdjo, 1989: 34). Penelitian induktif diawali dengan observasi atau pengamatan yang akan disajikan secara terukur sehingga menjadi data (Fuad Hasan dan Koentjaraningrat, 1977, Tanudirdjo, 1989: 18). Objek dan lokasi penelitian berupa tinggalan arkeologis yang berada di kawasan Bandar Udara Sam Ratulangi Manado.

Tahap penelitian yang digunakan meliputi persiapan, pengumpulan data, analisis data, dan kesimpulan. Tahap persiapan berupa kajian pustaka dan observasi awal pada objek penelitian sehingga dapat ditentukan permasalahan yang akan dibahas dalam penelitian. Pada tahap pengumpulan data, tidak hanya mendata artefak selaku data primer, namun juga arsip, gambar, foto dan juga peta kawasan selaku data sekunder baik yang didapat dari buku maupun internet. Tahap pengumpulan data objek penelitian dilakukan dengan melalui beberapa tahap, yaitu; studi pustaka, observasi lapangan, dan wawancara. Tahap analisis meliputi analisis morfologis, teknologi dan konteksual (Pusat Penelitian dan Pengembangan Arkeologi Nasional, 2008: 99-100).

\section{HASIL DAN PEMBAHASAN}

\section{Veilbox}

Veilbox merupakan bangunan pertahanan yang dibangun oleh Jepang pada masa Perang Dunia II. Umumnya berbentuk lingkaran atau persegi dengan pintu masuk dan terdapat beberapa lubang

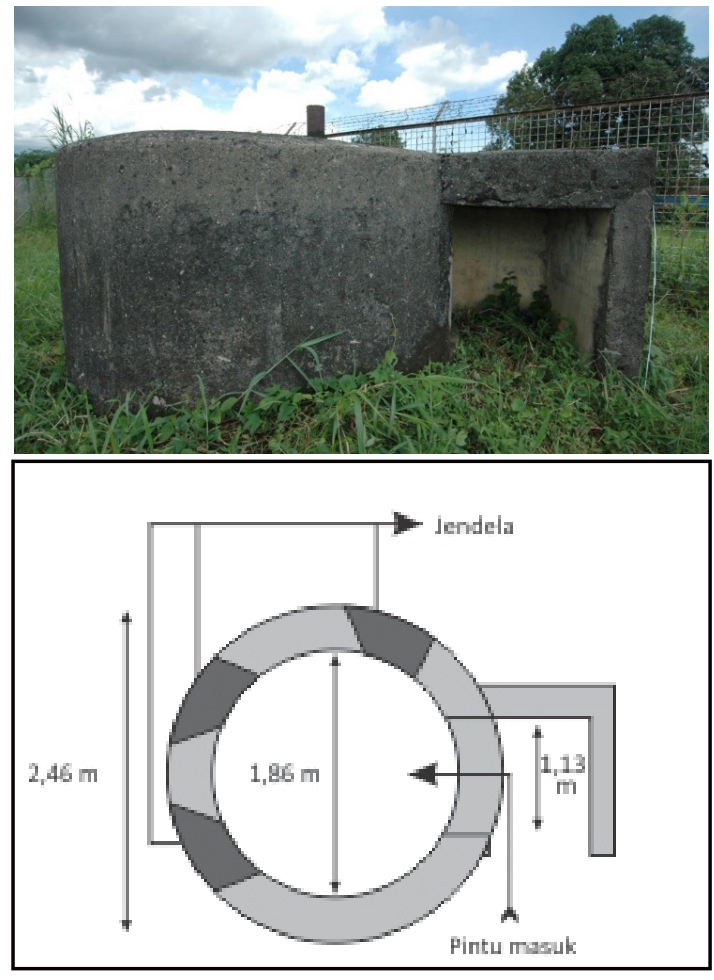

Gambar 2. Veilbox tampak depan (atas dan denah tampak atas (bawah) (Sumber: Balai Arkeologi Manado) 
bidik. Veilbox berasal dari bahasa Belanda veiligheid, yang berarti aman/keamanan (Wojowasito, 2000: 715) dan box yang berarti kotak (Wojowasito, 2000: 104). Veilbox berarti kotak tempat persembunyian yang aman, walaupun pada kenyataannya tidak selalu berbentuk kotak.

Bangunan veilbox kawasan Bandar Udara Sam Ratulangi terdapat di ujung Utara landasan pacu, berdekatan dengan pagar pembatas kawasan bandara. Secara astronomis terletak pada koordinat 1'32'09.43" LS dan 12455'25.46 BT dengan ketinggian $81 \mathrm{~m}$ dpl. Kondisi bangunan saat ini masih sangat baik walaupun kurang terawat. Bentuk veilbox di kawasan bandara Sam Ratulangi berbeda dengan yang ditemukan di kawasan lain. Umumnya bangunan veilbox berbentuk bulat dengan satu pintu masuk dan beberapa lubang bidik. Veilbox di Bandara Sam Ratulangi, pada bagian pintu masuk terdapat tambahan semacam teras, jadi secara keseluruhan tidak lagi berbentuk bulat. Terdapat satu pintu masuk berukuran 113 x $87 \mathrm{~cm}$, dan tiga lubang bidik berukuran $55 \times 30 \mathrm{~cm}$. Veilbox berukuran diameter dinding luar $246 \mathrm{~cm}$, diameter bagian dalam $186 \mathrm{~cm}$. Tebal dinding bagian atas $50 \mathrm{~cm}$, dan bagian samping 30 $\mathrm{cm}$. Bagian teras berukuran tebal dinding $25 \mathrm{~cm}$, dengan tinggi $123 \mathrm{~cm}$. Material bangunan terbuat dari beton spesi semen dengan rangka besi. Pada bagian atap terdapat dua ventilasi terbuat dari pipa besi.

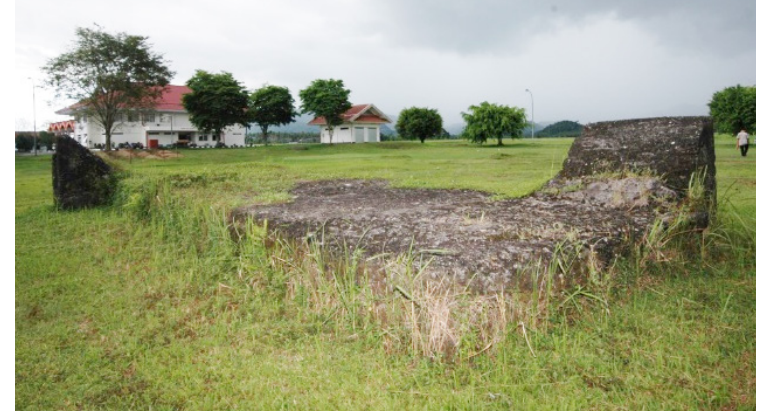

Gambar 3. Bungker tampak dari atas (Sumber: Balai Arkeologi Manado)

\section{Bungker}

Terletak di sebelah selatan kantor PT Angkasa Pura I, dengan koordinat 1'32'56.97" LS dan 124'55'23.69" BT dengan ketinggian $85 \mathrm{~m}$ dpl. Bangunan terlihat bagian pintu masuk dan atap bangunan. Kondisi bangunan saat ini masih dalam keadaan baik, namun kurang terawat. Bungker berbentuk memanjang utara selatan dengan ukuran bagian luar panjang $1030 \mathrm{~cm}$ dan lebar $370 \mathrm{~cm}$. Bagian atas yang terlihat dari permukaan tanah berukuran tinggi $60 \mathrm{~cm}$. Pintu masuk terletak di sebelah selatan menghadap kearah timur, sedangkan bagian selatan menghadap barat. Bentuk pintu masuk dari depan persegi dengan ukuran tinggi $150 \mathrm{~cm}$, dan lebar $80 \mathrm{~cm}$. Tebal dinding 20 $\mathrm{cm}$, dan terbuat dari beton dengan rangka besi. Bagian dalam berbentuk lorong dengan ukuran lebar $220 \mathrm{~cm}$, dan tinggi $160 \mathrm{~cm}$. Bagian langit-langit terdapat dua lubang ventilasi berukuran $30 \times 30$ $\mathrm{cm}$. Pintu masuk dari samping berbentuk segitiga. Lantai bangunan berupa tanah, dengan dinding terbuat dari beton. Bentuk bungker seperti ini mirip yang terdapat di Titiwungen Selatan Lingkungan 1, Kelurahan Sario. Berdasarkan Kamus Besar Bahasa Indonesia, kata bungker memiliki arti lubang perlindungan di bawah tanah atau ruangan yang dipakai untuk pertahanan dan perlindungan dari serangan musuh, biasanya berupa tumpukan pasir (Tim Penyusun, 1990: 137).

Secara umum bangunan pertahanan Jepang pada masa Perang Dunia II, bentuknya lebih sederhana dan tidak sebesar bangunan pertahanan yang dibangun bangsa Eropa, karena waktu pendudukan tentara Jepang yang relatif singkat dibandingkan Bangsa Eropa. Bangunan pertahanan Jepang dikembangkan secara khusus dan menyesuaikan dengan kondisi alam sekitar. Desain dan rangka dibuat lebih taktis dan sederhana, karena tidak memiliki waktu lama dalam pengerjaannya. Material bangunan pertahanan digunakan 
beton bertulang, batu karang dan kayu kelapa. Kekurangan bahan bangunan dan peralatan diimbangi dengan improvisasi menggunakan bahan yang tersedia di lingkungan sekitar. Konstruksi batu karang dan kayu kelapa terbukti andalan bagi Jepang, baik dalam ketersediaan dan tingkat perlindungan. Bentuk terowongan dan benteng bawah tanah merupakan bentuk pertahanan yang sesuai, namun pembangunannya membutuhkan waktu lama dan tenaga kerja besar (Verbeek, 2010: 48).

\section{Waruga}

Waruga terletak di halaman gedung kedatangan VIP Pemprov Suluawesi Utara. Secara geografis terletak pada koordinat $1^{\circ} 32^{\prime} 22.75 \mathrm{LS}$ dan $124^{\circ} 55^{\prime} 21.88^{\prime \prime} \mathrm{BT}$ dengan ketinggian $85 \mathrm{~m}$ dpl. Waruga merupakan peti kubur komunal yang terbuat dari batu tufa utuh. Penamaan waruga terdapat beberapa versi, antara lain moruga, maruga, wale morgha, dan wale ruga. Moruga merupakan bahasa Minahasa yang artinya direbus. Mayat diletakkan dalam waruga akan membengkak seolaholah direbus, dan akan hancur. Oleh sebab itu tempat meletakkan mayat disebut sebagai waruga atau tempat merebus. Wale morgha berarti rumah untuk badan yang kering, sedangkan wale ruga berarti rumah untuk badan yang hancur (Soegondho, 2008: 2-3).

Waruga terdiri dari dua bagian, yaitu bagian wadah dan penutup. Bagian wadah berbentuk kotak (persegi atau bujursangkar) dengan lubang untuk menaruh mayat di bagian tengahnya. Bagian tutup berbentuk segitiga atau limas seperti atap rumah. Pada beberapa waruga yang ditemukan di wilayah Minahasa, terdapat hiasan pada bagian badan atau tutup. Bentuk dan motif hiasan waruga berbeda-beda. Ada yang hanya terdapat pada bagian tutupnya saja, atau badannya saja, atau terdapat pada bagian wadah dan tutup.

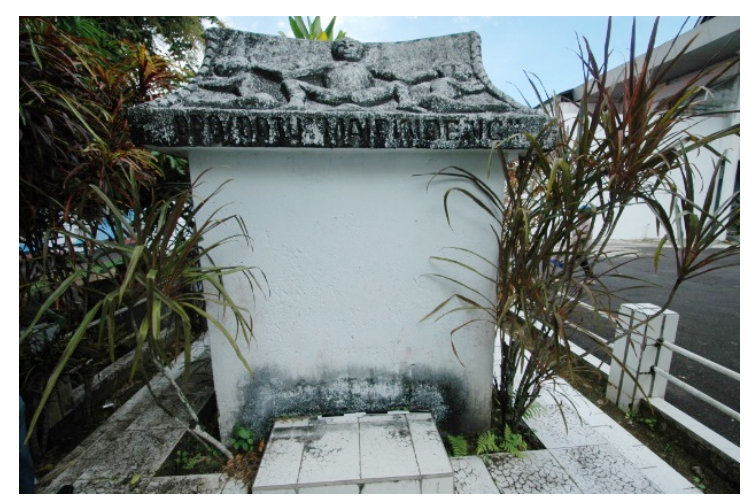

Gambar 4. Waruga

(Sumber: Balai Arkeologi Manado)

Berdasarkan hasil penelitian, teknik seni hias waruga di Minahasa terbagi menjadi teknik pahat dan gores. Sedangkan jenis motif yang ada dapat dikelompokkan menjadi lima, yaitu: motif binatang, manusia, tumbuhan, kombinasi, dan kendi/ jumbai (Fahriani, 2008: 32-33). Akhir penggunaan waruga sebagai penguburan diperkirakan sekitar tahun 1892, ketika terjadi wabah kolera di tanah Minahasa yang memakan korban meninggal banyak, sehingga tidak tersedia cukup waruga untuk menguburkan. Maka diambil kebijakan untuk menguburkan mayat dengan menggali kubur sesuai ajaran agama Kristen (Parengkuan, 2000: 5). Sedangkan menurut Marbun, berakhirnya penggunaan waruga dipengaruhi oleh masuknya agama Kristen di tanah Minahasa (Marbun, 2005).

Berdasarkan pengamatan di lapangan, waruga yang terdapat di kawasan Bandar Udara Sam Ratulangi telah mengalami renovasi, terutama pada bagian badannya. Bagian badan sudah disambung dengan semen, sehingga ukuran yang sebenarnya susah untuk diketahui dengan pasti. Bagian asli terdapat pada bagian bawah badan. Sedangkan bagian penutup masih asli menggunakan batu domato. Penutup waruga terdapat hiasan pola manusia kangkang pada keempat sisinya. Pada salah satu sisi penutup waruga terdapat pahatan tulisan Opo Dotu Mairendeng. Ini merupakan nama dari si mati yang dikubur dalam waruga. 
Waruga berukuran tinggi badan 134 $\mathrm{cm}$ dan lebar $127 \mathrm{~cm}$. Bagian penutup berukuran tinggi $73 \mathrm{~cm}$, dengan panjang bagian bawah $154 \mathrm{~cm}$ dan bagian atas $143 \mathrm{~cm}$. Lebar bagian penutup berukuran $150 \mathrm{~cm}$.

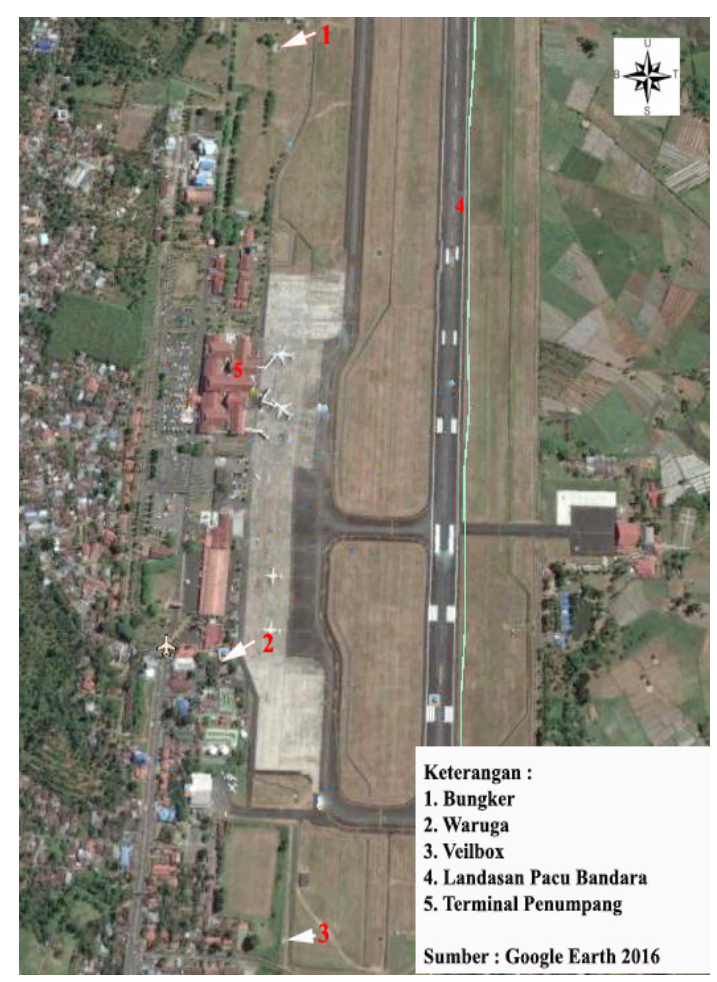

Gambar 5. Peta keletakan tinggalan arkeologi (Sumber: Google Earth 2016)

\section{Pelestarian}

Tinggalan arkeologis yang terdapat di kawasan Bandar Udara Sam Ratulangi dapat dikategorikan dalam Benda Cagar Budaya. Berdasarkan UU No. 11 Tahun 2010 Pasal 1 ayat 2, yang dimaksud Benda Cagar Budaya adalah benda alam dan/atau buatan manusia, baik bergerak maupun tidak bergerak, berupa kesatuan atau kelompok, atau bagian-bagiannya, atau sisa-sisanya yang memiliki hubungan erat dengan kebudayaan dan sejarah perkembangan manusia. Selain itu kriteria lain adalah mempunyai nilai penting sejarah, ilmu pengetahuan, pendidikan, agama, dan atau kebudayaan. Berdasarkan hal tersebut, maka tinggalan arkeologi di dalam kawasan Bandar Udara Sam Ratulangi dapat dikelompokkan dalam Benda Cagar Budaya, walaupun belum ditetapkan sebagai Benda Cagar Budaya oleh Pemerintah. Untuk itu perlu adanya upaya pelestarian tinggalantinggalan tersebut agar tidak rusak dan hilang.

Hakikat pelestarian adalah upaya agar suatu cagar budaya tetap berada atau kembali berada dalam konteks budaya yang masih hidup. Dalam proses pelestarian, yang dilestarikan bukan hanya unsur bendawi saja, namun juga unsur tak bendawi, yaitu nilai penting yang terkandung di dalam cagar budaya (Tanudirdjo, 2008: 5-7). Pelestarian bukan hanya terhadap bendanya saja, tetapi juga meliputi kawasan sekitarnya. Seiring dengan perkembangan waktu, terjadi perubahan cara pandang pelestarian Cagar Budaya, yaitu:

1. Pelestarian bukan hanya sekedar bendanya saja (object oriented), melainkan termasuk lingkungan sekitarnya.

2. Pelestarian tidak hanya ditujukan untuk memenuhi kebutuhan akademis saja, tetapi untuk kepentingan kesejahteraan masyarakat luas.

3. Pemanfaatan benda cagar budaya bukan semata-mata berorientasi profit, melainkan lebih mengutamakan benefit (Soeroso, 2006).

Dengan demikian, pelestarian cagar budaya tidak lagi hanya menjadi tanggung jawab pemerintah saja, namun juga memerlukan peran aktif dari masyarakat.

Dalam upaya pelestarian Benda Cagar Budaya tentunya berpedoman pada UU No. 11 tahun 2010 tentang Cagar Budaya. Pengertian pelestarian menurut UU No. 11 tahun 2010 adalah " upaya dinamis untuk mempertahankan keberadaan Cagar Budaya dan nilainya dengan cara melindungi, mengembangkan dan memanfaatkannya."

Berdasarkan hal tersebut, maka upaya pelestarian Cagar Budaya meliputi kegiatan perlindungan, pengembangan dan pemanfaatan Cagar Budaya. 


\section{Perlindungan}

Pengertian perlindungan berdasarkan UU No. 11 tahun 2010 adalah upaya mencegah dan menanggulangi dari kerusakan, kehancuran, atau kemusnahan dengan cara penyelematan, pengamanan, zonasi, pemeliharaan, dan pemugaran Cagar Budaya”. Dalam upaya perlindungan tentunya perlu diperhatikan adanya prinsip keaslian Benda cagar Budaya, yaitu; keaslian bahan (material), bentuk (desain), teknologi pengerjaan, dan keaslian tata letak. Upaya perlindungan dapat dikelompokkan menjadi dua, yaitu perlindungan secara fisik dan non fisik. Perlindungan secara fisik meliputi perlindungan terhadap Cagar Budaya, dilakukan dengan penyelamatan, pengamanan, zonasi, pemeliharaan, konservasi, dan pemugaran. Upaya penyelamatan bagi tinggalan arkeologi dapat dilakukan dengan cara melindungi dari kerusakan yang diakibatkan oleh binatang (rayap dan serangga), tumbuhan (jamur) dan iklim (cuaca, curah hujan dan kelembaban). Upaya pengamanan dapat dilakukan dengan membuat pagar sebagai pembatas bangunan Cagar Budaya dengan lingkungan sekitarnya. Selain itu juga dibuat papan himbauan supaya masyarakat mengetahui dan ikut mengamankan keberadaan bangunan Cagar Budaya yang ada (Marzuki, 2012: 190-193).

Zonasi adalah penentuan batasbatas keruangan situs Cagar Budaya dan kawasan sesuai dengan kebutuhan. Tujuan pokok yang hendak dicapai dalam zonasi (pembagian kawasan cagar budaya) adalah :

a. Untuk melindungi, mengamankan, dan mencegah berbagai kerusakan yang akan terjadi terhadap peninggalan purbakala di dalam satuan-satuan ruang tersebut.

b. Memberi fasilitas, mengatur, dan mengendalikan berbagai kegiatan yang direncanakan di dalam satuan-
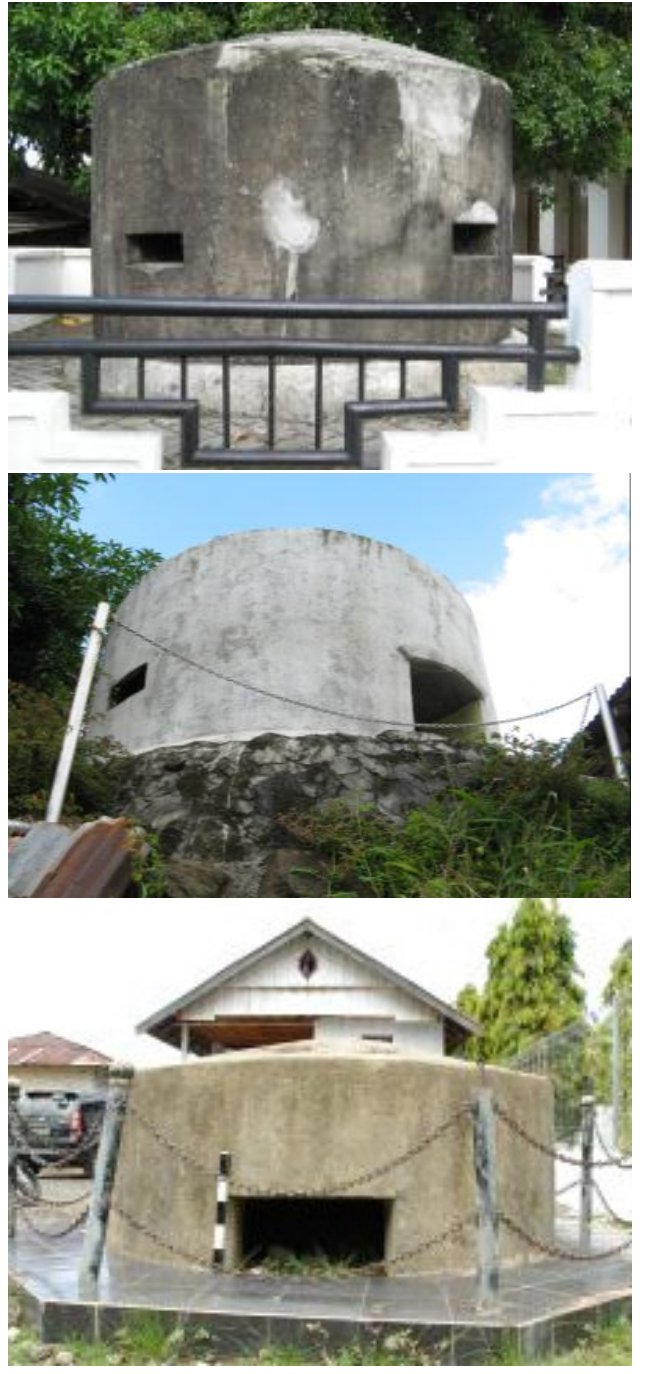

Gambar 6. Contoh pagar perlindungan veil box (Sumber: PDAI dan pribadi).

satuan ruang secara bertanggung jawab, terarah, bertahap, dan terpadu untuk kemanfaatan nasional (Soeroso, 2006: 3).

Pemugaran (restoration), adalah upaya untuk mengembalikan sebuah objek pada keadaan yang sebenarnya dengan tanpa menggunakan bahan-bahan baru. Pemugaran dapat dilakukan sejauh bukti-bukti yang ada dapat mendukung untuk mengembalikan objek sesuai dengan keadaan aslinya dan apa adanya (Soebroto, 1997: 10, dan Soebroto, 2003: 4). Tujuan pemugaran adalah untuk meneruskan pusaka budaya yang kita warisi dari nenek moyang untuk anak cucu kita. Untuk menjaga jangan sampai 
yang kita wariskan hasil rekayasa kita, dan bukan pusaka nenek moyang, maka harus diterapkan kaidah-kaidah arkeologi seketat mungkin (Santoso, 2004).

Upaya perlindungan Cagar Budaya di kawasan Bandar Udara Sam Ratulangi sebagian sudah dilaksanakan, namun kurang sesuai dengan prinsip keaslian. Perlindungan yang kurang sesuai dengan prinsip keaslian dilakukan terhadap tinggalan waruga di halaman gedung Pemda Sulut. Badan waruga yang tersisa bagian bawah dibangun kembali seperti semula dengan menggunakan material semen. Perlindungan yang dilakukan seharusnya tidak mengubah atau mengganti tinggalan arkeologi yang ada dengan bahan yang tidak sesuai. Material waruga berupa batu domato, diganti menggunakan material semen yang tidak sesuai aslinya. Seharusnya kondisi badan waruga yang tinggal bagian bawah dibiarkan, dan diberi pagar serta atap untuk melindungi dari kerusakan yang lebih parah.

Bangunan veilbox dan bungker saat ini belum ada upaya perlindungan. Pihak PT Angkasa Pura I selaku pengelola Bandar Udara berupaya untuk melakukan langkah tersebut. Hal ini dengan adanya perhatian dari pihak Angkasa Pura untuk meminta Balai Arkeologi Manado melakukan penelitian sebagai bahan acuan untuk upaya tersebut. Kondisi bangunan veilbox dan bungker tidak mengalami perubahan, masih sebagaimana aslinya. Upaya perlindungan yang bisa dilakukan dengan memberi pagar pembatas dan jalan setapak di sekitar veilbox dan bungker. Perlindungan dengan membuat atap bangunan tidak memungkinkan, karena lokasinya berada di area steril yang berdekatan dengan landasan pacu. Berkaitan zonasi kawasan, sesuai UU. No. 11 Tahun 2010, pembagian zonasi dibagi menjadi: zona inti, penyangga, pengembangan, dan penunjang. Zonasi yang dilakukan terhadap tinggalan arkeologi di kawasan Bandar Udara Sam Ratulangi tentunya berbeda dengan tinggalan yang berada di tempat lain. Hal ini dikarenakan lokasi tinggalan yang berada dalam area terbatas. Zonasi yang dapat dilakukan berupa zona inti, dan zona penyangga saja. Zona inti berupa lokasi tinggalan arkeologi dan sekitarnya dengan radius sekitar 2-3 $\mathrm{m}$. Zona penyangga, berupa daerah di luar zona inti. Luasan zona inti dengan radius tidak terlalu luas dikarenakan area sekitar tinggalan yang terbatas.

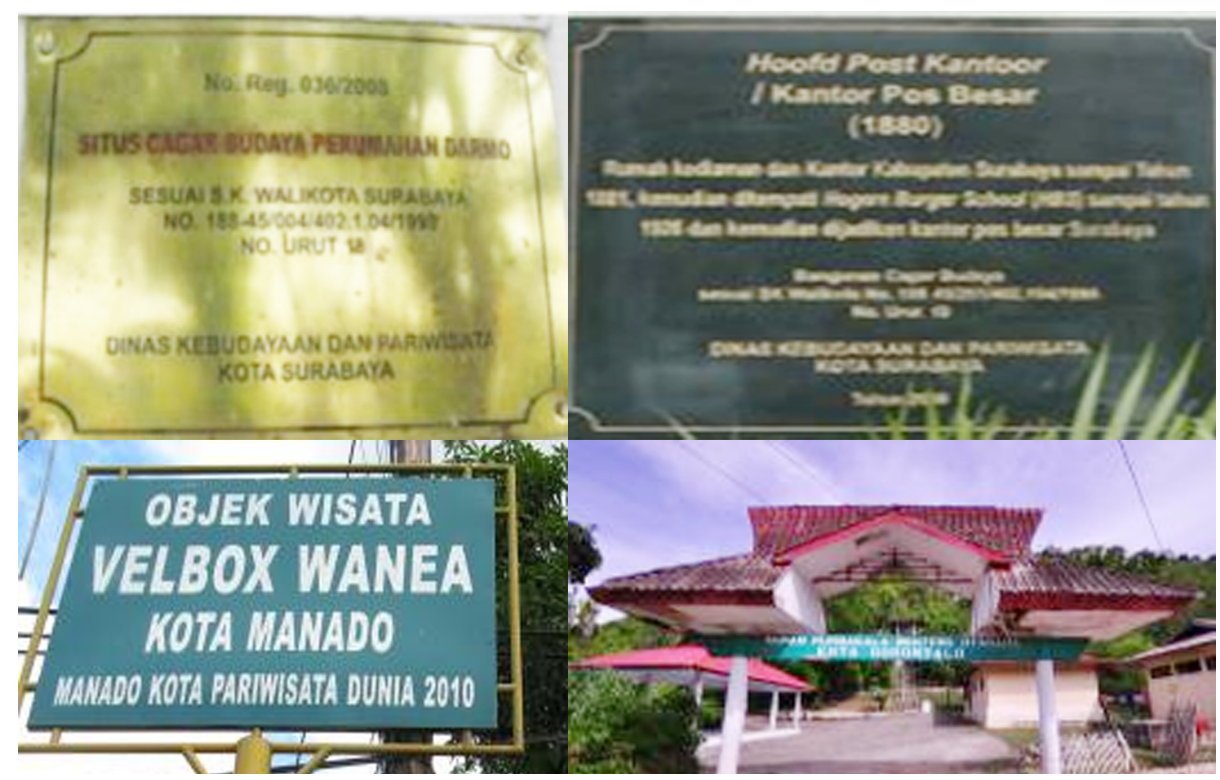

Gambar 7. Contoh papan nama Benda Cagar Budaya (Sumber: Balar Manado, Balar Yogyakarta, dan PDAI) 
Upaya perlindungan secara hukum dapat dilakukan dengan membuat papan pengenal Benda Cagar Budaya. Karena berada dalam kawasan terlindung, maka kondisi Benda Cagar Budaya di kawasan Bandar Udara Sam Ratulangi belum mengalami kerusakan akibat ulah manusia. Namun tidak menutup kemungkinan adanya oknum yang kurang bertanggungjawab akan merusaknya. Patut dihargai upaya pihak PT Angkasa Pura untuk berperan aktif dalam upaya pelestarian Cagar Budaya di wilayahnya.

\section{Pengembangan}

Bangunan Cagar Budaya dapat dikembangkan untuk kepentingan ilmu pengetahuan, pariwisata, sejarah, dll. Pengembangan Cagar Budaya perlu dilakukan dengan serasi, selaras, dan seimbang dalam memenuhi tuntutan berbagai kepentingan jangka panjang (Ronald, 1999). Berdasarkan penuturan Junius Ferdinand Walenta (Finance \& IT Dept. Head PT Angkasa Pura I), bangunan Cagar Budaya yang berada di kawasan Bandar Udara Sam Ratulangi akan dikembangkan untuk ilmu pengetahuan dan pariwisata. Pihak bandara sering mendapat kunjungan dari siswa sekolah (TK sampai perguruan tinggi) untuk melihat-lihat kawasan bandara. Bangunan Cagar Budaya yang ada akan dikembangkan sebagai salah satu daya tarik wisata sejarah yang ada di kawasan Bandar Udara Sam Ratulangi, sehingga nantinya dapat menjadi nilai tambah bagi Bandar Udara Sam Ratulangi.

\section{Pemanfaatan}

Benda Cagar Budaya dapat dimanfaatkan untuk berbagai kepentingan, tidak hanya kepentingan akademis saja, namun dapat dimanfaatkan secara ekonomis. Berdasarkan UU No. 11 tahun 2010, Benda Cagar Budaya dapat didayagunakan untuk kepentingan sebesarbesarnya kesejahteraan rakyat dengan tetap mempertahankan kelestariannya. Kegiatan pemanfaatan Cagar Budaya harus berbanding lurus dengan pelaksanaan pelestarian (Wahyu, 2011:175-176). Pelaksanaan pemanfaatan harus seimbang, dengan kegiatan pelestarian. Pemanfaatan yang berlebihan dapatmengancam, merusak, atau bahkan memusnahkan objek tinggalan Cagar Budaya (Chawari, 2008:159). Saat ini, tinggalan Cagar Budaya yang terdapat di kawasan Bandar Udara Sam Ratulangi belum dimanfaatkan secara maksimal. Pihak Angkasa Pura I berencana untuk memanfaatkan tinggalan Cagar Budaya di wilayahnya. Pemanfaatan Cagar Budaya dapat dilakukan untuk kepentingan agama, sosial, pendidikan dan ilmu pengetahuan, teknologi, kebudayaan dan pariwisata. Berdasarkan hal tersebut, pemanfaatan Cagar Budaya di kawasan Bandar Udara Sam Ratulangi dikelompokkan dalam pemanfaatan bidang pendidikan dan ilmu pengetahuan, kebudayaan dan pariwisata.

- Pendidikan dan ilmu pengetahuan

Benda Cagar Budaya dapat digunakan sebagai sarana pendidikan khususnya mengenai sejarah keberadaan Bandar Udara Sam Ratulangi. Bangunan veilbox dan bungker dapat dijadikan sebagai bukti bahwa Bandar Udara Sam Ratulangi menjadi sejarah dalam Perang Dunia II. Selain itu juga menjadi bagian sejarah pemberontakan Permesta di Sulawesi Utara.

\section{- Kebudayaan}

Bangunan waruga merupakan salah satu hasil kebudayaan masyarakat kuno Minahasa. Pada bagian tutup waruga terdapat hiasan ukiran dengan motif manusia kangkang.

- Pariwisata

Tinggalan sumber daya arkeologi yang terdapat di kawasan Bandar Udara Sam Ratulangi dapat menjadi salah satu daya tarik pariwisata dipadukan dengan wisata sejarah dan ilmu pengetahuan. 
Berkaitan dengan usaha pemanfaatan dalam bidang pendidikan dan pengetahuan, kebudayaan, serta pariwisata, langkah yang dapat dilakukan pihak PT Angkasa Pura yaitu:

a. Membuat jalur kunjungan dan menyediakan pemandu bagi wisatawan yang bermaksud mengunjungi tinggalan-tinggalan arkeologi tersebut. Penyediaan pemandu berkaitan dengan lokasi tinggalan yang berada di zona steril bagi pengunjung, sehingga perlu dipandu agar tidak membahayakan bagi pengunjung dan lalu lintas penerbangan.

b. Membuat papan petunjuk dan informasi mengenai adanya tinggalan arkeologi di tempat-tempat strategis, seperti : pintu masuk kawasan bandara, lapangan parkir, terminal kedatangan, dan keberangkatan. Papan petunjuk dan informasi berisi foto-foto bandara Sam Ratulangi pada masa Perang Dunia II dengan bangunan veilbox dan bungkernya. Informasi lain bisa berupa brosur atau selebaran yang berisi uraian sejarah bandara dan bangunan-bangunan yang diberikan kepada pengunjung

Berdasarkan hal tersebut, bangunan Cagar Budaya dapat dilestarikan namun tetap memberikan manfaat bagi pemerintah daerah, pemilik, dan masyarakat sekitar. Untuk dapat menjadikan pelestarian bangunan bersejarah mampu mendatangkan keuntungan finansial, pemegang kekuasaan dan pencari keuntungan harus bersedia dan berminat menjadi mitra dari para perencana kota dan masyarakat. Apabila dikelola secara profesional, pelestarian dapat memberikan keuntungan untuk bisnis serta keuntungan pajak untuk khas daerah. Keterlibatan pemerintah daerah, sektor swasta, dan seluruh masyarakat sangat diperlukan untuk mengelola suatu upaya pelestarian (Budihardjo, 1997: 223).

\section{KESIMPULAN}

Terdapat beberapa peninggalan arkeologi yang sampai saat ini masih dalam keadaan baik di kawasan Bandar Udara Sam Ratulangi Manado. Peninggalan tersebut berupa kubur batu waruga, veilbox, dan bungker peninggalan Jepang pada masa Perang Dunia II. Peninggalan kubur batu waruga berada di halaman kantor kedatangan VIP Pemprov Sulawesi Utara, dan saat ini sudah mengalami renovasi. Peninggalan veilbox dan bungker belum mengalami perubahan, walaupun kondisinya kurang terawat. Peninggalan-peninggalan tersebut dapat dilestarikan untuk kepentingan dimasa yang akan datang. Upaya pelestarian yang dapat dilakukan meliputi perlindungan, pengembangan dan pemanfaatan. Upaya perlindungan dengan cara perlindungan fisik dan non fisik. Upaya pengembangan dan pemanfaatan dilakukan untuk kepentingan ilmu pengetahuan, sejarah, pendidikan, pariwisata, dan kebudayaan. Keberadaan tinggalan waruga Opo Dotu Mairendeng di kawasan Bandar Udara Sam Ratulangi membuktikan kawasan tersebut memiliki peran semenjak dahulu. Opo Dotu merupakan tokoh yang dituakan dan dihormati oleh masyarakat Minahasa pada masa lalu. Keberadaan veilbox dan bungker digunakan untuk mempertahankan lapangan terbang dari serangan Belanda pada Perang Dunia II.

\section{Ucapan Terima Kasih}

Penulis mengucapkan terimakasih kepada Bapak Junius Ferdinand Walenta (Finance \& IT Departement Head)PT Angkasa Pura I Manado beserta staf yang telah memberikan ijin dan menemani ke lokasi selama proses penelitian. 


\section{DAFTAR PUSTAKA}

Budihardjo, Eko. (1997). Tata Ruang Perkotaan. PT Alumni, Bandung.

Chawari, Muhammad. (2008). Bangunan Rumah Tradisional Jawa di Kampung Kauman Yogyakarta. Yogyakarta: Tesis Program Pasca Sarjana Universitas Gadjah Mada.

Fahriani, Ipak. (2008). Deskripsi Waruga, Bentuk, Ukuran, dan Hiasannya, dalam Waruga Peti Kubur Batu dari Tanah Minahasa Sulawesi Utara. Manado: Balai Arkeologi Manado.

Fuad Hasan dan Koentjaraningrat. (1977). Beberapa Asas Metodologi Ilmiah. Metodologi Penelitian, Koentjaraningrat (ed), Masyarakat. Jakarta: Gramedia.

Makkelo, Ilham D. (2010). Kota Seribu Gereja Dinamika Keagamaan dan Penggunaan Ruang di Kota Manado. Yogyakarta: Penerbit Ombak.

Marbun, Jhohanes. (2005). Faktor Penyebab Hilangnya Tradisi Penguburan Dengan Waruga di Minahasa (Sulawesi Utara). Yogyakarta: Skripsi Sarjana Fakultas Ilmu Budaya. Universitas Gadjah Mada.

Marzuki, Irfanuddin Wahid. (2012). Pola Keletakan Bangunan Indis di Kota Gorontalo dan Strategi Pelestariannya. Yogyakarta: Tesis Program Pasca Sarjana Universitas Gadjah Mada.

Palar, H.B. (2009)a. Wajah Baru Minahasa. Bogor: Yayasan Gibbon. (2009)b. Minahasa Benteng Terakhir NKRI. Bogor: Yayasan Gibbon.

Parengkuan. (2000). Kuburan Sebagai Obyek Pengkajian Sejarah, Makalah Seminar Arkeologi. Manado: Balai Arkeologi Manado.

Pusat Penelitian dan Pengembangan Arkeologi Nasional. (2008). Metode Penelitian Arkeologi. Jakarta: Puslitbang Arkenas.

Ronald, Arya. (1999). Studi Penggalian dan Inventarisasi Benda Benda Budaya di Provinsi Daerah Istimewa Yogyakarta. Yogyakarta: Dinas Kebudayaan Pemprov Daerah Istimewa Yogyakarta.
Santoso, Dukut. (2004). Prinsip-prinsip dan Metodologi Konservasi dan Pemugaran Benda Cagar Budaya. Makalah Diklat Konservasi Tingkat Menengah Angkatan III. Balai Konservasi Borobudur.

Saptaningrum, Irna. (2010). Kajian BentukBentuk Pertahanan Militer Masa Kolonial Belanda di Kota Manado. Laporan Penelitian Arkeologi. Manado: Balai Arkeologi Manado.

Soebroto, Ph. (1997). Kondisi Situs Trowulan dan Usaha-usaha Pelestariannya. Sarasehan Tentang Pelestarian BCB. Pacet.

----------. (2003). Pemanfaatan Benda Cagar Budaya Bangunan Bata Pasca Pugar Untuk Kepentingan Pendidikan dan Ilmu Pengetahuan dalam Makalah Rapat Penyusunan Kebijakan Pemanfaatan Benda Cagar Budaya. Cisarua.

Soegondho, Santoso. (2008). Akar Budaya Waruga di Tanah Minahasa Sejarah, Fungsi, dan Pertanggalannya. dalam Waruga Peti Kubur Batu dari Tanah Minahasa Sulawesi Utara. Manado: Balai Arkeologi Manado.

Soeroso. (2006). Prinsip-prinsip Pelestarian Kawasan BCB. Materi Diklat Konservasi dan Pemugaran Tingkat Menengah. Yogyakarta: Balai Konservasi Peninggalan Borobudur.

Sumanto. (1995). Metodologi Penelitian Sosial dan Pendidikan. Yogyakarta: Penerbit Andi Offset.

Tanudirdjo, Daud Aris. (1989). Ragam Metode Penelitian Arkeologi dalam Skripsi Karya Mahasiswa Arkeologi Universitas Gadjah Mada. Laporan Penelitian. Yogyakarta: Fakultas Sastra Universitas Gadjah Mada.

-...-...- (2008) Melestarikan Warisan Budaya Kita. Bahan Penyuluhan tentang Cagar Budaya. Yogyakarta tanggal 24 Juni 2008.

Tim Penyusun. (1990). Kamus Besar Bahasa Indonesia. Jakarta: Balai Pustaka. 
Verbeek, John. (2010). Japanese Fortifications in Indonesia an introduction, dalam Inventory and Identification Forts in Indonesia. Jakarta: Pusat Dokumentasi Arsitektur.

Wahyu, Harry Trisatya. (2011). Pelestarian dan Pemanfaatan bangunan Indis di Kawasan Kota Baru. Yogyakarta: Tesis Universitas Gadjah Mada.

Wojowasito, S. (2000). Kamus Umum Belanda Indonesia. Jakarta: Ichtiar Baru Van Hoeve.

ww w.samratulangi-airport.com/ sejarah, diunduh tgl 22 Juni 2014.

http://collectie.tropenmuseum.nl/Default. aspx, diunduh tanggal 22 Juni 2014.

UU. No. 11 Tahun 2010 Tentang Cagar Budaya 